\title{
SISTEM INFORMASI PROGRAM KELUARGA HARAPAN STUDI KASUS KECAMATAN KOSAMBI TANGERANG
}

\author{
Nora Fitriawati ${ }^{1}$, Arief Herdiansah ${ }^{2}$, Adi Gunawan ${ }^{3}$ \\ 1 Universitas Bina Nusantara / Fakultas Teknik, Teknik Informatika \\ JI. Kyai H. Syahdan No.9, Kemanggisan, DKI Jakarta 11480, TLP 5345830 \\ 2Universitas Muhammadiyah Tangerang / Fakultas Teknik, Teknik Informatika \\ JI. Perintis Kemerdekaan 1/33 Cikokol Kota Tangerang TLP. 55793251 \\ 3 Universitas Raharja Tangerang / Fakultas Sain dan Teknologi, Sistem Informasi \\ Jl. Jenderal Sudirman No.40 Cikokol Kota Tangerang TLP. 5529692
}

1'Nora.fitriawati@Binus.edu , 2arief_herdiansah@umt.ac.id, 3adigunawan@raharja.info

\begin{abstract}
ABSTRAK, Dalam rangka menjalankan penyaluran dana pemerintah berkaitan dengan penyaluran dana bantuan program "Keluarga Harapan" diperlukan sebuah sistem informasi berbasis komputer yang dapat menunjang kegiatan staf/pegawai kecamatan dalam mengelola data warga sehingga hasil pengolahan data menghasilkan akurasi tinggi terhadap informasi warga kurang mampu yang berhak menerima penyaluran dana bantuan program "Keluarga Harapan". Penelitian ini menggunakan tabel elisitasi dalam mengalisa sistem yang dibutuhkan pengguna dan menggunakan Unified Modelling Language (UML) dalam rangka visualisasi, spesifikasi, konstruksi dan pendokumentasian sistem yang dikembangkan. Sistem program keluarga harapan dikembangkan menggrunakan bahasa PHP (Hyppertext Preprocessor) dengan database MySQL. Hasil dari penelitian ini diharapkan dapat mempermudah staf kelurahan dalam melakukan pengelolaan data warga sehingga pempinan dapat mengambil kebijakan penyaluran dana bantuan program "Keluarga Harapan" dengan tepat dan akurat.
\end{abstract}

Kata Kunci : Dana bantuan, Data Warga, Keluarga Sejahtera, Elisitasi, UML.

\begin{abstract}
In distributing government funds related to the distribution of "Keluarga Harapan" program donations of hope a computer-based information system is needed that can support the activities of staff/sub-district staff in managing citizens' data so that the results of data processing produce high accuracy of information on the poor who are entitled to receive aid funds distribution of "keluarga Harapan" programs. This research uses elicitation tables in analyzing the system needed by the user and using the Unified Modeling Language (UML) in the framework of visualization, specifications, construction and documentation of the developed system. The "Keluarga Harapan" system program was developed using the PHP (Hyppertext Preprocessor) language with a MySQL database. The results of this study are expected to make it easier for government staff to manage citizens' data so that management can take the policy of channeling aid funds to the "Keluarga Harapan" program appropriately and accurately.
\end{abstract}

Keywords: Relief funds, Citizen Data, Prosperous Families, Elicitation, UML. 


\section{PENDAhUluan}

Salah satu proram Pemerintah saat ini adalah meningkatkan kesejahteraan warga negara, salah satunya dengan memberikan bantuan berupa dana yang disalurkan melalui kecamatan kepada warga yang kurang mempu untuk dijadikan modal usaha agar warga tersebut dapat meningkat kesejahteraannya, program ini dinamakan program keluarga sejahtera.

Dengan berkembangnya kemajuan teknologi informasi berbasiskan komputer, dapat membuat pekerjaan yang dilakukan menjadi lebih tertata rapih, cepat dan akurat. Sistem adalah jaringan prosedur yang dibuat menurut pola yang terpadu untuk melaksanakan kegiatan pokok perusahaan sedangkan prosedur adalah suatu urutan kegiatan/pekerjaan klerikal, biasanya melibatkan beberapa orang dalam satu departemen atau lebih yang dibuat untuk menjamin penanganan secara seragam untuk transaksi perusahaan yang terjadi secara berulang-ulang ${ }^{[5]}$.

Pengolahan data warga di kecamatan Kosambi Kabupaten Tangerang yang dilakukan saat ini masih memiliki beberapa kekurangan diantaranya, dalam pencatatan data warga kurang mampu. Pengolahan data masih belum terkomputerisasi dengan baik, hal ini mengakibatkan kualitas informasi yang dihasilkan kurang akurat. Sedangkan kualitas informasi tergantung dari tiga hal, yaitu: Akurat (Accurate), Tepat Waktu (Timelines) dan Relevan (Relevance) $)^{[8]}$.

Oleh karena itu perlu dikembangkan sebuah sistem komputerisasi pengolahan data warga dari sisi tingkat ekonomi, sehingga program penyaluran dana bantuan program keluarga harapan dapat tersalurkan dengan akurat. Sistem yang dikembangkan merupakan sebuah Management Information System yaitu sebuah sistem terkomputerisasi

\subsection{Rumusan Masalah}

Permasalahan penelitian dapat dirumuskan sebagai berikut:

1. Bagaimana perancangan sistem informasi data kependudukan berdasarkan tingkat kemampuan ekonomi berbasis web dapat diterapkan pada Kecamatan Kosambi Kab. Tangerang?

2. Bagaimana sistem informasi yang dikembangkan dapat mengelola data warga kurang mampu sehingga dapat dijadikan acuan dalam pengambilan keputusan penyaluran dana keluarga sejahtera? yang melakukan pengolahan data agar bisa digunakan oleh orang yang membutuhkannya ${ }^{[4]}$. Untuk proses pengembangan sistem, peneliti menggunakan XAMPP, karena Dalam XAMPP sudah terdapat Apache (web server), MySQL (database), PHP (server side scripting), Perl, FTP server, Php MyAdmin dan pustaka lainnya ${ }^{[3]}$.

\subsection{Identifikasi Masalah}

Dalam proses penyaluran dana bantuan bagi keluarga yang kurang mampu atau dana bantuan keluarga sejahtera, ada beberapa kendala yang dihadapi:

1. Belum tersedia sebuah sistem database warga dari sisi tingkat kemampuan ekonomi warga.

2. Masih ditemukan ada beberapa yang seharusnya berhak menerima dana bantuan keluarga sejahtera, tetapi tidak mendapatkan bantuan tersebut.

3. Pihak kecamatan memilki sesulitan dalam menentukan siapa saja yang paling berhak mendapat dana bantuan keluarga sejahtera.

4. Berlum tersedianya sistem yang membantu pengukuran tingkat keberhasilkan penyaluran dana keluarga sejahtera.

\subsection{Batasan Masalah}

penelitian ini dibatasi dengan batasan sebagai berikut:

1. Merancang dan membangun sebuah sistem informasi data kependudukan berdasarkan tingkat kemampuan ekonomi berbasis web.

2. Mengimplementasikan sistem informasi yang mengelola data warga kurang mampu sebagai dasar pengambilan keputusan penyaluran dana keluarga sejahtera.

\section{LANDASAN TEORI}

\subsection{Tinjauan Pustaka}

\subsubsection{Definisi Model Waterfall}

Metode waterfall adalah sebuah metode yang memberikan gambaran pendekatan yang sistematis dan juga berurutan pada pengembangan perangkat lunak, dimulai dengan spesifikasi kebutuhan pengguna lalu berlanjut melalui tahapan perencanaan (planning), permodelan (modeling), konstruksi (construction), serta penyerahan sistem ke para pelanggan atau pengguna (deployment), yang diakhiri dengan dukungan pada 
perangkat lunak lengkap yang dihasilkan/after implementation support[6].

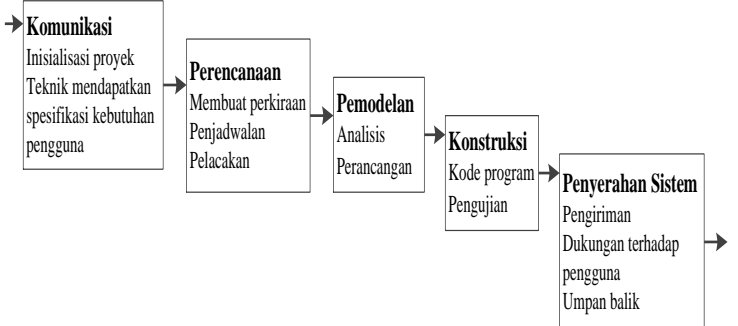

Gambar 1.1. Tahapan Model Waterfall

\subsubsection{Konsep Pengolahan Data}

Pengolahan data dapat diuraikan menjadi dua, yaitu: Penyimpanan Data dan Penanganan Data ${ }^{[8]}$.

a. Penyimpanan Data (Data Storage) meliputi pekerjaan pengumpulan (filing), pencarian (searching), dan pemeliharaan (maintenance). Data disimpan dalam suatu tempat yang lazim dinamakan "file". File dapat berbentuk map, ordner, disket, tape, hard disk, dan lain sebagainya.

b. Penanganan Data (Data Handling) meliputi berbagai kegiatan seperti: pemeriksaan, perbandingan, pemilihan/sortir, peringkasan, dan penggunaan.

\subsection{Tinjauan Studi}

Tinjauan studi merupakan uraian tentang teori, temuan, dan bahan penelitian lainnya yang diperoleh dari bahan acuan untuk dijadikan landasan kegiatan penelitian untuk menyusun kerangka pemikiran yang jelas dari perumusan masalah yang ingin diteliti, tinjauan studi penelitian ini:

1. Penelitian yang dilakukan oleh Dwi Arinda Pritasari dan Reza Zuhara Purnamasari (2014) yang berjudul "Perancangan Sistem Informasi Dalam Pemberian Beras Miskin (Raskin) Pada Warga Kelurahan Minggir". Penelitian ini membahas perancangan dan pembangunan sistem informasi pendataan rakyat miskin untuk program beras miskin (raskin). Dalam laporan penelitiannya, penulis menjabarkan masalah yang dihadapi adalah pendataan rakyat miskin yang belum terkomputerisasi sehingga menyulitkan pihak yang berwenang dalam proses pendistribusian beras raskin. Hasil penelitian adalah terbentuknya rancangan dan sebuah sistem informasi terkomputerisasi menggunakan Microsoft Visual Studio Ultimate 2012 dan SQL Server 2008 untuk mempermudah kinerja pegawai dalam memasukkan data warga miskin, sehingga dihasilkan laporan yang menjadi acuan penyebaran beras raskin yang lebih akurat.

2. Penelitian yang dilakukan oleh Usman Ependi (2012) yang berjudul "Sistem Informasi Pemetaan Data Penduduk Miskin Di Kabupaten Ogan Komering Ulu Sumatera Selatan". Sistem informasi pemetaan data penduduk miskin ini menggunakan metode pengembangan sistem web engginering. Setelah melakukan tahapan formulation, planning, analysis, engineering, implementation, testing dan customer evaluation deployment hasil penelitian adalah perancangan basis data, perancangan proses serta antar muka sistem informasi pemetaan data penduduk miskin kabupaten Ogan Komering Ulu berbasis web, yang dapat memetakan data penduduk miskin.

\section{METODOLOGI PENELITIAN \\ 3.1 Jenis Penelitian}

Penelitian ini merupakan penelitian dan pengembangan yang memiliki keterlibatan intens peneliti dengan masalah dan objek penelitian. Titik berat penelitian ini adalah pada perubahan dan mengatasi masalah nyata di objek penelitian, sehingga terdapat kontribusi nyata dan langsung terhadap objek penelitian dalam mengatasi masalah tersebut.

\subsection{Metode Pemilihan Sample}

Metode pemilihan sample yang digunakan adalah purposive sampling. Pengambilan sampel dengan purposive sampling merupakan teknik pengambilan sampel dengan mengambil responden dipilih oleh peneliti menurut ciri-ciri spesifik yang dimiliki sampel. Pemilihan sampel responden yang disertakan dalam proses pengumpulan informasi berdasarkan pertimbangan kriteria yang telah ditentukan sebelumnya, yaitu memiliki peran dalam proses penyeleksian dan pendistibusian dana bantuan keluarga sejahtera.

\subsection{Metode Pengumpulan Data}

Metode pengumpulan data adalah teknik atau cara-cara yang dapat dilakukan oleh peneliti untuk mengumpulkan data [2].

Metode pengumpulan data yang digunakan adalah metode campuran dimana dilakukan pengumpulan data dengan cara penyebaran daftar peryataan dan melakukan wawancara/intervivew. 


\subsection{Teknik Analisis Sistem}

Peneliti teknik analisis pendekatan Object Oriented Analysis (OOA) atau analisis berorientasi objek, menggunakan alat bantu UML dimana untuk proses analisis sistem yang dikembangkan disesuaikan dengan hasil tahapan pengumpulan data yang diperoleh, yaitu dari hasil wawancara, survey, observasi langsung dan studi pustaka yang peneliti lakukan agar sesuai dengan spesifikasi kebutuhan sistem sesuai keinginan pengguna.

\subsection{Desain Penelitian}

Desain penelitian adalah kerangka kerja yang digunakan untuk melakukan penelitian. Desain sistem yang dikembangkan sesuai dengan gambar III-1, III-2 dan III-3 dibawah ini.
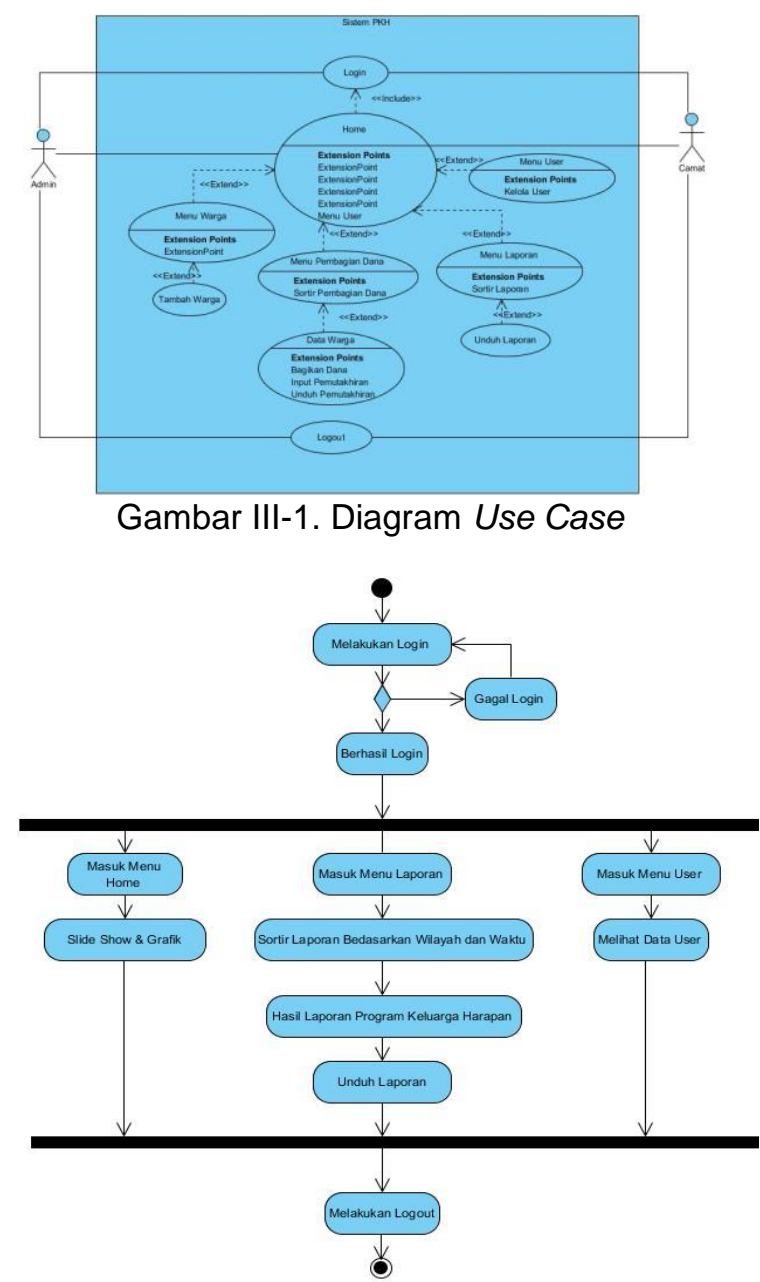

Gambar III-2. Diagram Activity

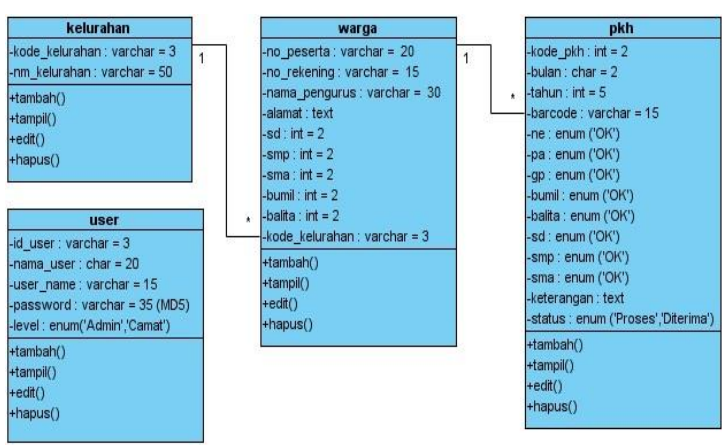

Gambar III-3. Diagram Class

\section{HASIL PENELITIAN}

\subsection{Tampilan Login}

Untuk dapat masuk ke sistem informasi program keluarga harapan pengguna harus login.

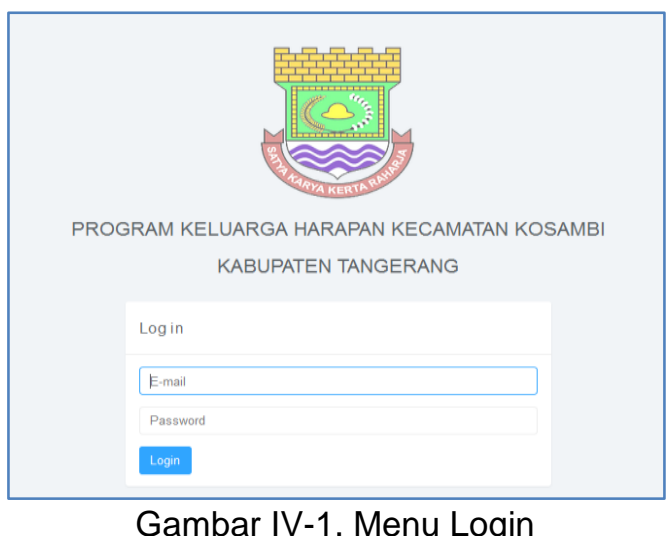

\subsection{Tampilan Menu Login}

Setelah user melakukan Login, jika berhasil maka akan tampil tampilan berikut ini:

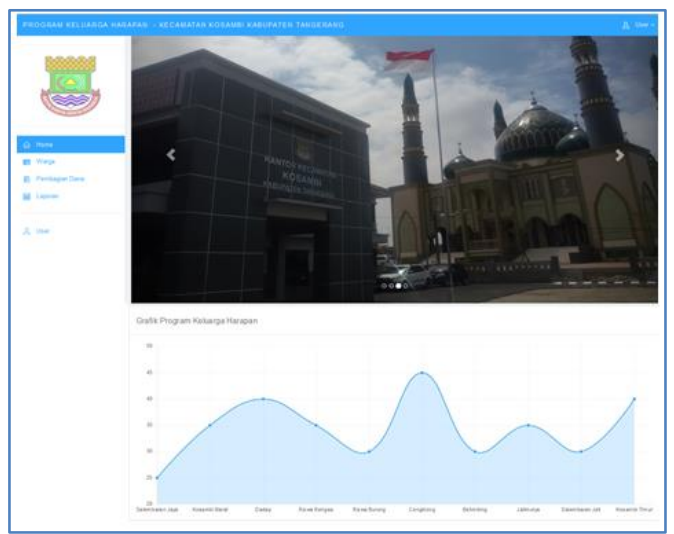

Gambar IV-2 Menu Utama

\subsection{Dashboard Data Warga}

Dashboard pada penelitian ini menampilkan daftar warga kecamatan kosambi . 


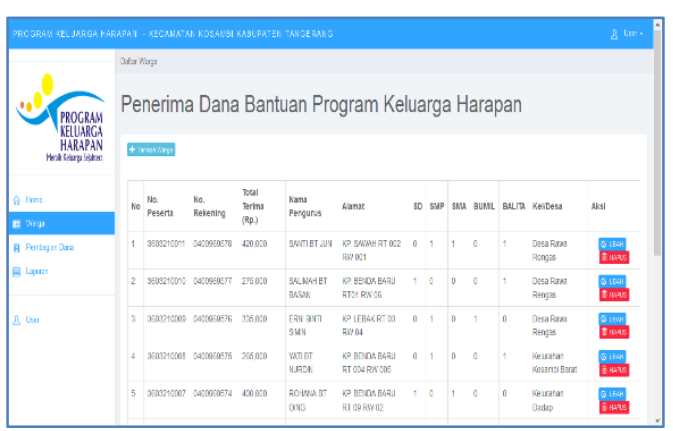

Gambar IV-3 Tampilan Dashboard Data Warga

\subsection{Dasboard Dana Program Keluarga Sejahtera}

Salah Dasboard yang dihasilkan dari penelitian ini adalah daftar informasi keluarga yang berhak menerima dana program keluarga sejahteraa dan informasi penyaluran dana program tersebut kepada warga yang berhak sesuai dengan data yang dimiliki.

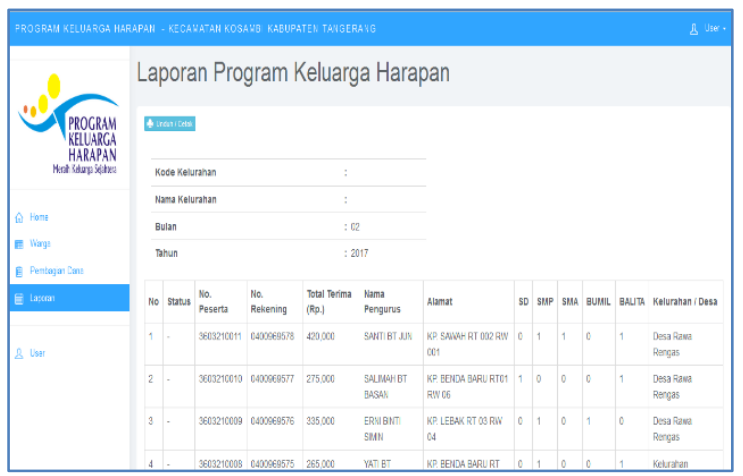

Gambar IV-4. Tampilan Dashboard

Penyaluran Dana Program Keluarga sejahtera

\subsection{Print-out Laporan Distribusi Dana Program Keluarga Sejahtera}

Laporan akhir dari sistem yang dikembangkan adalah laporan kepada siapa saja dana program keluarga sejahtera tersebut disalurkan, sebagaimana gambar dibawah ini:

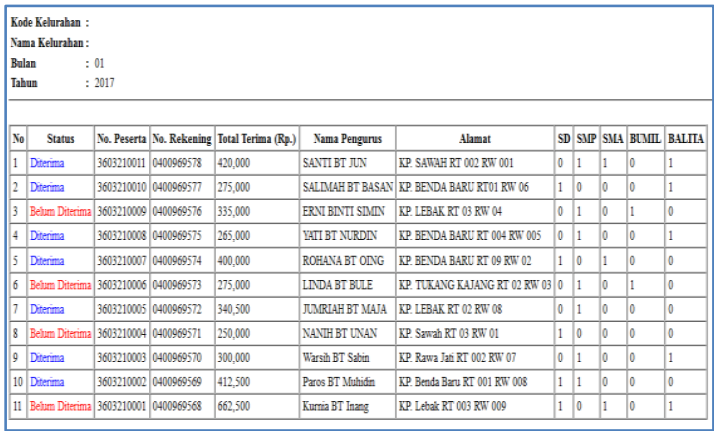

Gambar IV-4. laporan Monitoring Penyaluran Dana Program Keluarga sejahtera

\section{KESIMPULAN}

Berdasakan uraian pada penulisan hasil penelitian diatas, kesimpulan yang dapat peneliti sampaikan sebagai berikut:

1. Perancangan sistem informasi data kependudukan yang dihasilkan telah didisain untuk dapat melakukan penyimpanan dan pengkategorian data warga berdasarkan tingkat kemampuan ekonomi.

2. Sistem informasi keluarga harapan yang dikembangkan dapat mengelola dan menghasilkan laporan data warga kurang mampu, sehingga dapat dijadikan acuan dalam pengambilan pimpinan (camat) dalam menentukan keputusan kepada siapa saja penyaluran dana keluarga sejahtera disalurkan.

3. Sistem informasi yang dikembangkan berbasis web menggunakan data base MySql, shingga dalam proses implementasi tidak memerlukan resource hardware dan software pendukung yang berkapasitas besar.

\section{DAFTAR PUSTAKA}

[1] Ependi, Usman. 2012. Sistem Informasi Pemetaan Data Penduduk Miskin di Kabupaten Ogan Komering Ulu Sumatera Selatan. Digital Information \& System Conference. Sumatera Selatan Palembang.

[2] Guritno, Sudaryono dan Untung Rahardja, 2011, Theory and Application of IT Research, Yogyakarta, Andi Offset

[3] Kartini., Fahnun.U.B., Pratiwi, D., 2013. Perancangan Sistem Informasi Pemesanan Tiket Konser Musik Online Berbasis Lokasi. Jurnal Prosiding Seminar Nasional Teknologi Informasi 
dan Multimedia Semnasteknomedia STMIK AMIKOM. Yogyakarta.

[4] Mulyani, Sri, 2016, Metode Analisis dan Perancangan Sistem, Edisi Kedua. Bandung, Abdi Sistematika.

[5] Mulyadi, 2010, Sistem Akuntansi. Jakarta, Salemba Empat.

[6] Pressman, S.R, 2015, Rekayasa Perangkat Lunak-Pendekatan Praktisi Buku I, Yogyakarta, Andi.
[7] Pritasari, A.D., Purnamasari, Z.R., 2014. Perancangan Sistem dalam Pemberian Beras Miskin (Raskin) pada Warga Kelurahan Minggir. Naskah Publikasi. STMIK AMIKOM. Yogyakarta

[8] Sutabri, Tata, 2012, Konsep Sistem Informasi. Yogyakarta, Andi. 